\title{
Scams, Heists, and Racial Disidentification: Joanne the Scammer at the Intersection of Queer of Color Critique and Digital Blackness
}

\author{
Kidiocus King-Carroll \\ University of Minnesota, Twin Cities
}

Abstract: Internet personality Branden Miller has performed many drag personas, but it wasn't until 2015 and the creation of his latest persona, Joanne the Scammer, that Miller broke through the popular culture zeitgeist. The ethnically ambiguous and self-proclaimed Caucasian Joanne wears blonde wigs, furs, and chain-smokes Newport cigarettes while proclaiming her love for "robbery" and "fraud." In her first video appearance in 2015, posted on social networking site Instagram, Joanne stares into the camera and declares: "I just want to let you girls know that I'm a real messy bitch-a liar, a scammer. I love robbery and fraud. I'm a messy bitch who lives for drama." Branden Miller as Joanne the Scammer has become a popular culture phenomenon. Miller's characterization of Joanne speaks to deeper cultural implications of race, class, gender, identity performance, and sexuality. Through an engagement with Jose Esteban Muñoz's theory of disidentification and Aurora Chang's conceptualization of the racial queer, this article uses a queer of color critique analysis to argue that Branden Miller's embodiment of the Joanne the Scammer persona is a racially queer disidentificatory practice embedded in a critique of whiteness and white supremacy.

Branden Miller is a black biracial former sex worker who is best known by his stage name of Joanne the Scammer. Miller identifies as gay, and before the success of his campy Joanne the Scammer persona had previously performed in character as Miss Prada, a transgender sex worker, for nearly five years on YouTube videos that amassed up to 500, 000 views. Miller first rose to mainstream prominence in an Instagram video posted in early 2015. In the video, a messily wigged Miller stares into the camera and declares: "I just want to let you girls know that I'm a real messy bitch-a liar, a scammer. I love robbery and fraud. I'm a real messy bitch who lives for drama."[1]

While Miller had performed previous drag personas before the emergence of Joanne the Scammer, arguably none have been as successful as the Joanne character-Branden Miller as Joanne the Scammer has 2.5 million followers across Instagram, Twitter, and Facebook, was featured on the 2016 MTV Video Music Awards, and was also widely adopted as a Halloween costume in 2016. Miller, often in character as Joanne the Scammer, has been profiled, interviewed, and written about in publications such as Dazed Digital, The Fader, Complex Magazine, Paper Magazine, and People Magazine. The way in which Miller has been "taken up" in mainstream discourse is evidence of his appeal in the online world; Miller regularly interacts with celebrities online and in the real world, but the largest signifier of his success is his popularity on social networking platforms, Twitter and Instagram. 
Miller also frequently interacts with fans, and his Twitter posts are consistently liked and retweeted by up to 100,000 people. Miller's memes, pictures, and short videos on Instagram are also liked by hundreds of thousands of people and watched by over 2 million.

Through a queer of color critique framework, I argue that Miller's performance of Joanne is a racially queer disidentificatory practice embedded in a critique of whiteness and white supremacy. Miller's critique can be further contextualized in the field of Digital Blackness. I examine three objects in Miller's cultural archive to consider the ways in which Miller's identity informs his characterization of Joanne the Scammer and the deeper cultural implications surrounding identity performance and critiques of whiteness and white supremacy. The Joanne Scamming Network with Joanne the Scammer (2016) is the first object that I am considering -the video is widely circulated, has 2 million views across Facebook and YouTube and is also a significant example of the way Miller uses drag, farce, and blackface reversal as a racially queer disidentificatory practices. The second object that I am considering is Caucasian Living with Joanne the Scammer (2016); Caucasian Living has also been widely circulated and has a total of 1.8 million views across Facebook and YouTube. The third object that I consider in this analysis is an untitled video released in the wake of the 2016 United States Presidential Election. Untitled (2016) is a one minute and thirty second advertisement for a Joanne the Scammer product; although it is not as widely circulated as the other two objects (it has 1.3 million views across social media platforms), it is a significant example of the way that Miller uses whiteness to critique white supremacy. Furthermore, through analyzing these objects, I contend that the online world (and thus Digital Blackness) is an essential component to an understanding of Miller's performance of Joanne the Scammer as a racially queer disidentificatory practice.

Black people's place in the online world has been a subject of discourse amongst black scholars, thinkers, creatives, and activists for more than 25 years. In a speech at the "Black Nations, Queer Nations?" conference in New York City in 1995, Essex Hemphill pondered the (im)possibility of queer black futures in cyberspace. Hemphill states - "I stand at the threshold of cyberspace and wonder, is it possible that I am unwelcome here, too? Will I be allowed to construct a virtual reality that empowers me?" [2] Hemphill stood on a precipice of uncertainty - he was unsure as to what futurity the digital world held for him as a black gay man with AIDS and as to whether it could be a place of empowerment. Christina Sharpe articulates Hemphill's ambivalence in "Racialized Fantasies on the Internet," maintaining that Hemphill's fears are that the "virtual may not sufficiently allow for meaningful departures from the real." [3] Sharpe states that:

\footnotetext{
Like Hemphill, I wonder what subject positions cyberspace allows, enables, and forbids: I wonder what indignities and humiliations might follow me there. Unlike him, however, I am less interested in constructing an empowering virtual reality than I am in teasing out the possibility that interactions in cyberspaces might help reformulate some preconceptions about race and certain reproductions of the knowable racialized subject. Race as we encounter it in technoculture forces us to reconsider scientific, personal, and more general formulations and meanings of race. The virtuality of race in cyberspace begins to expose it as already a virtual construction in real life. ${ }^{[4]}$
}

Hemphill's and Sharpe's ambivalences about the (im)possibilities of the digital world at the turn of the $21^{\text {st }}$ Century were not unfounded - the abstracting racism, terror, and violence of the real world have certainly accompanied black people into online space. In "Digital Whiteness, Primitive Blackness," Janelle Hobson contends that "power dynamics that exist offline get reproduced online and in dominant media in disturbing and retrogressive ways," ${ }^{[5]}$ particularly for black women whose subjectivities are often erased, bodies are reobjectified, and are made even more vulnerable to the violence of the offline world through the "easy access" of digital technologies. Indeed, the racial and gendered violence that black people have experienced offline has 
transmogrified in the online world - the fears that Hemphill and Sharpe express are real and ever-present as black abjection is frequently reinforced and circulated online. Social media is often a forum through which visuals of black dying and death are regularly posted and reposted in the interest of disseminating information about antiblack violence. l'd argue that these visually descriptive efforts often serve the destructive libidinal interests of whiteness and state power through an overexposure of the dead black body that borders on the pornographic. Still, this could be considered one reason why the online world is such a cogent point of departure from which to engage the study of black life. Yet, what is most compelling about Hemphill's, Sharpe's, and Hobson's articulations for my argument is that they interrogate the possibilities of black and queer futurity in cyberspace. They speculate and formulate thought about fear and invisibility that are important to imagining the digital world/digital technologies as a space where black/black queer people have been abused and erased but have also still managed to produce deeply creative and reflexive work that speaks to various aspects of black lived experience and can also function as resistance to white supremacy, antiblackness, and black queer and trans antagonisms.

In Distributed Blackness: African American Cybercultures, André Brock Jr. argues that black people's place within the digital world has been characterized in terms of exclusion. The black body has only ever been read in terms of its absence from the digital sphere, but this has changed within the last five years as black people have interacted with digital technology in a myriad of innovative ways even though black activist, political, and cultural contributions are rarely recognized or compensated. Brock states:

...Online identity has long been conflated with whiteness, even as whiteness is itself signified as a universal, raceless, technocultural identity. By this I mean that whiteness is what technology does to the Other, not the technology users themselves. The visibility of online Blackness can be partially attributed to the concentration of Black folk in online spaces that are not exclusively our own: we are finally present online in ways that the mainstream is unable to disavow. ${ }^{[6]}$

Through their cultural productions, Miller and other black content creators such as Patti LaHelle or Kid Fury and Crissle allow us to witness black people's place in the online world beyond technological exclusion and the abjection that has followed black people into the online world. I believe that Digital Blackness is thus an apt means of describing black digital presence-the digital world is no longer the sole domain of whiteness. Blackness has qualified the absent but ever-present whiteness that the term "digital" has signified and transformed it into a site of black/black queer possibility. Moreover, I believe it is vital to configure Digital Blackness as a queer space that challenges heteronormative logics of belonging. Hemphill asks: "Is it possible that I am unwelcome here, too?" There is no easy answer because exclusion and violence have followed black queer people into mediated digital spaces like Twitter, and Hemphill's question remains as relevant as it did in 1995. Black queer and black trans folks are frequently subject to antagonism because of their blackness, queerness, and transness on Twitter and elsewhere in digital space. Still, black queer cultural workers like Miller may allow for an imagining of a possibility beyond such violence through the fraught act of taking up space and doing it blackly and queerly as a means of empowerment.

In an interview with hip-hop magazine, The Fader, Miller discusses the ambiguity surrounding his upbringing and his identity as a black gay man. Miller says that his biological parents were Puerto Rican and black, yet as a child, for a period, he grew up believing that he was white. In the interview, Miller states that: 
I went to an all-black school, and people would say, 'Branden, you're black,' or 'Branden, you're adopted,'” he says. "I was like, 'No, actually l'm white.'” He laughs about it now but remembers the discovery as traumatic. "That was tragic, l'm not going to lie. I found out I was adopted, and then I found out I was black. I was like, oh shit, none of these people are really related to me at all! That was fucking..." He stops for a second. "I thought I was white. I had white friends. I was a white person! I still have moments where I'm like, Oh my God. That's really awkward. ${ }^{[7]}$

Miller's struggle with his racial identity operated in confluence with his burgeoning sexuality. In the interview, Miller discusses having to come to terms with his racial identity and gayness in a homophobic household, challenges that he began to channel through his performance of drag. Miller looked to the online world and drag performance as a mode of catharsis and of achieving success. Miller's racial identity also heavily informs his cultural praxis. Joanne frequently slips in and out of her Caucasian identity when she doesn't look or feel glamorous or when she is planning a scam. In a September 10th, 2016 Twitter post, there is a picture of Joanne in a wig made of Senegalese Twists with the caption: "Not so Caucasian tonight betch. On my way to the drug lord's house, little does he know under this is a blonde bob." [8] Other identifiers of Joanne's racial ambiguity can be found in her practices: Joanne chain-smokes Newport cigarettes, a brand largely targeted to and smoked by African American men, and frequently gets into fights with her "ethnic" ex-boyfriend and his "ethnic" girlfriend who are coded as black. Joanne largely identifies as white, but she frequently takes on an "ethnic" identity and is often identified by white outsiders as "ethnic" (black and Latinx) in many of Miller's cultural productions. Joanne the Scammer is both a reflection of the racial anxieties and conflict that Miller has expressed about his upbringing and a disidentificatory critique of class and whiteness.

The disidentificatory nature of Miller's cultural work takes shape in The Joanne Scamming Network with Joanne the Scammer (TJSN). Joanne's TJSN is a parody of the Home Shopping Network. Joanne, attired in her signature fur and blonde wig, and a similarly dressed white woman, sell heisted burner phones for exorbitant prices. The video transitions into the opening sequence of Joanne's show, which is comprised of various still shots of Joanne in a variety of poses as the words "Caucasian" and "messy bitch" scroll across the screen. In the opening lines of the video, Joanne says: "Welcome back to JSN where we sell things that matter, honestly, today we're going to be selling the Joanne the Scammer starter pack."[9] The first item in the Joanne the Scammer starter pack consists of a "Joanne the Scammer Persian Llama Fur Coat" that retails for $\$ 4752.93$, but that Joanne sells for $\$ 7,888.80$. The model, whom Joanne refers to as a "pretty Caucasian," walks onto the set and begins modeling the coat. Joanne fondles the coat and declares: "This is Persian Llama, it feels real soft, and it looks good on white titties."[10] Miller continues to build upon this construction, as Joanne later sells a wig that she calls "nappy," which is often a code used to describe "unruly" black hair, and that she claims is critical to the Joanne the Scammer starter pack. She expresses disbelief and jealousy when she realizes that her Caucasian model's blonde hair is real, and she does not in fact wear a wig like Joanne does.

The next item that Joanne sells is a pack of Newport cigarettes; Joanne says: "If you want to be a scammer like me, you got to have the Newports."[11] Joanne then associates whiteness with smoking and Caucasian glamour, claiming that Newport's are the official cigarette of Caucasians as she attempts to have her resistant model place the cigarettes in her mouth. In this scene, Joanne must teach the white model that smoking Newport cigarettes is the correct way of practicing white womanhood-a framework that deviates from the model's own code of whiteness, a code that Joanne consistently miscodes in this section as well as throughout the entirety of the video. 


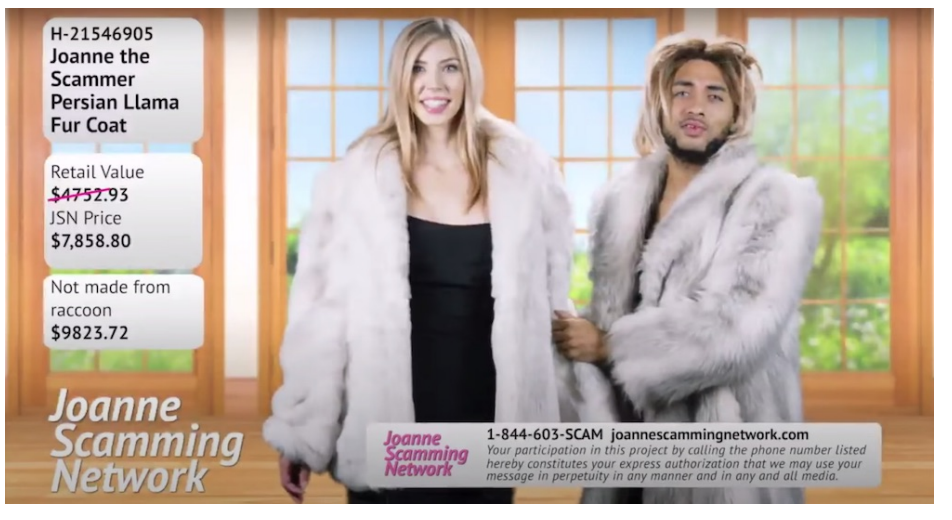

Figure 1. Still taken from The Joanne Scamming Network with Joanne the Scammer.

After attempting to sell her overpriced cigarettes, Joanne sells the item that she contends is the most essential for scamming and heists, a ski mask. Joanne states: "Now this ski mask is amazing. I have done 95 heists, I've robbed over thousands of banks with this, and it's because of this thing right here,"[12] she says as she grips the head of the terrified model wearing the ski mask. Joanne's anger and frustration at the woman's deviation from Joanne's code of white womanhood culminates in her becoming physical with the model. The video then ends abruptly because Joanne claims that the producers of her show are receiving calls from

viewers angry about the content.

The concept of authenticity or realness is a key factor in TJSN; Joanne consistently calls upon the idea of authentic whiteness while expressing jealousy of her phenotypically Caucasian model, whose hair is "real" and not a wig. The idea of authenticity also factors into Joanne's articulation of what it takes to embody her, a glamorous Caucasian woman. In Miller's conceptualization, a glamorous Caucasian woman wears exotic furs, dons blonde wigs, smokes Newport cigarettes, and engages in heists and scams while wearing the ever-essential ski mask. Beyond Joanne's jealousy of her Caucasian model, there is tension between what Joanne understands to be Caucasian womanhood and the white womanhood that her model presents in proclaiming that her hair is real and resisting when Joanne forces her to place cigarettes in her mouth. This is not Joanne's understanding of white womanhood and her conception frequently comes into conflict with the white women that she comes into contact with throughout Miller's cultural productions. These white women are frequently scared, confused, and/or aggressive towards Joanne who they read as decidedly not white.

Miller's disidentificatory praxis takes form in TJSN. In Disidentifications: Queers of Color and the Performance of Politics, José Esteban Muñoz defines disidentification as a "hermeneutic," a system of production, a performance methodology. Disidentificatory practice moves between the two poles of reception and production. Muñoz argues that the essence of disidentification is an ambivalent methodology that cannot be understood as a "restrictive or 'masterfully' fixed manner of identification."[13] Disidentification is a mode of survival that is utilized by a "minority spectator" to withstand and contradict socially narrow standards of identification. Muñoz writes:

\footnotetext{
Disidentification is about recycling and rethinking encoded meaning. The process of disidentification scrambles and reconstructs the encoded message of a cultural text in a fashion that both exposes the encoded message's universalizing and exclusionary machinations and recruits its workings to account for, include, and empower minority identities and identifications. Thus, disidentifications is a step further than cracking open the code of the majority; it proceeds to use this code as raw material for representing a disempowered politics or positionality that has been rendered unthinkable by the dominant culture. ${ }^{[14]}$
}

In TJSN, in Joanne's attempt (and failure) to embody glamorous white womanhood, we can locate disidentificatory practice through Miller's construction of a code that de-normalizes and destabilizes heteropatriarchal norms, and that builds salient critiques of whiteness and white supremacy. While Joanne aspires to model white womanhood with her unwilling model as an avatar of what she considers the right way to be white, she consistently associates that whiteness with a glamour predicated on criminality and antiblackness. 
In Caucasian Living with Joanne the Scammer, the establishing shot is of Joanne fleeing through the backyard of a white and pristine gated mansion; this transitions into the title sequence and Joanne welcomes the viewer and the cameraman into her "Caucasian home" before bragging about her Malaysian Bamboo floors. Joanne says: "This is my house. This is how I live, honestly, this is me, all me," [15] as she guides us into the foyer, a flute of champagne in her right hand. The symbolism of the video is nearly transparent; the whiteness of the house and the owner's Caucasian identity are very clearly connected, and the inside of Joanne's "Caucasian home" is as white and pristine on the inside as it is on the outside.

Joanne takes us into her kitchen and attempts to describe the different appliances, but it soon becomes apparent that she is not able to accurately describe or work said appliances. Joanne walks us over to a television with a security camera setup and seems slightly worried as she describes how she likes to watch the security cameras for pleasure-it becomes evident that this is one of Joanne's scams. Joanne proceeds to open her refrigerator and begins pointing to different items she that she can't identify or pronounce, similarly to the appliances, before gesturing to a carton of brown eggs. She says: "We have colored eggs. Now, I know l'm white, um, but white people have colored eggs. As I like to call them, minority eggs. Real good, I like to crack them open. Real messy. And um, apples and strawberries, everything a rich white woman would have."[16] As in TJSN, Miller consistently uses racial politics, farce, and camp as tools of disidentifying -in Miller's queer world building, even eggs have a racial identity.

Miller infuses his work with references to what I am identifying (by way of Aurora Chang) as racial queerness. Although Miller does not specifically identify as racially queer, his articulation of the ambiguity surrounding his race in The Fader, and the way that this is channeled in his embodiment of Joanne and her understanding of race vis-à-vis brown eggs, might be understood within the framework of Chang's conceptualization of the racial queer. Chang writes:

I use the term, racial queer, to frame the politicized space of the Multiracial individual. I use this term to convey queerness (both as a term of empowerment and derogation) as captured by being Multiracial. I draw from two primary definitions of what it means to queer... To queer - to make strange, to frustrate, to counteract, to delegitimize, to camp up heteronormative knowledges and institutions, and the subjectivities and socialities that are (in)formed by them and that (in)form them... queerness extends beyond its origins in sexuality to all acts of counterhegemony. ${ }^{[17]}$

Building upon Gloria Anzaldúa's theory of Borderlands and framing herself within this articulation, Chang further writes:

She [Anzaldúa] insists that there is something compelling about being both male and female [intersexuality] as I believe there is for being both one race and another (or more). Queerness, then, for the multiracial individual may denote both deviance (from the monoracial norm) and a unique individuality (stemming from one's Multiracial background). My experiences speak to this notion $-\mathrm{I}$ am both deviant and curiously anomalous. ${ }^{[18]}$

Miller's racially queer praxis also characterizes the latter half of the video. After giving a tour of her kitchen, Joanne proceeds into the living room, followed by the cameraman, and brags about her zebra print chairs: "I paid P. Diddy two million dollars to beat the shit out of zebras. And look at the result, he made me chairs." ${ }^{19]}$ She then walks us over to a collection of framed photos of white passing individuals and puts one of the pictures up to her face, claiming that the woman in the picture is her mother and that she, Joanne, is the young girl beside the mother in the photo. This moment in Miller's performance is resonant with his own articulation of growing up as a child with white adoptive parents and believing that he himself was white. Joanne then cycles through more of the 
framed photos; providing commentary on the lives of her white relatives, she says: “...my grandpa, what a handsome white man. Honestly, he owned SunCo, he also created the electric toothbrush, very white, I know."[20] Throughout Miller's performance in this section of the video, whiteness is associated with high socioeconomic status, a construction that Miller elevates to nearly absurd levels in Joanne's discussion of her zebra print chairs and her wealthy white grandfather's empire.

Joanne then escorts us into her bedroom closet and rummages through the clothing, discussing the quality of different items. She picks up a dress and discusses the different times that she's worn it for trips to a shooting range with the actress Kirstie Alley. In Miller's cultural production, Joanne frequently invokes her relationship with Alley; in Joanne's worldview, Alley is seemingly the personification of the glamorous conservative white womanhood that she aspires to embody, and her relationship with Alley legitimates Joanne's status as a glamorous self-interested white woman. ${ }^{[21]}$ Joanne then walks over to the jewelry case in "her" closet and discusses the genealogy of the different jewels as she places certain pieces in the pockets of her fur coat-this action amplifies the fact that this tour of her "Caucasian home" is indeed a scam, a heist. After exiting her closet Joanne takes us on a tour of her bathroom and asks the cameraman to turn off the camera, which he doesn't, as she rummages through different cabinets and drawers, pocketing various pharmaceuticals.

As Joanne prepares to take us on a tour of her backyard, she finds that the back door is locked and attempts to open it as the security cameras show a white woman walking to the front door of the mansion. The woman comes upon Joanne and screams: "What is going on in here? Who are you?"[22] Joanne attempts to pretend as if the woman is her Latinx maid, Mrs. Gonzalez, (who is angry because Joanne has not paid her) as the woman begins to question Joanne's identity. Joanne's framing of the woman as her Latinx maid is a clear articulation of Joanne's understanding of Caucasian identity - not only do white people have high socioeconomic statuses but they also have Latinx domestic workers that they take advantage of and mistreat. This element of Miller's disidentificatory performance is an evident critique of whiteness and white supremacy in that it reveals the racism and xenophobia inherent to whiteness, which the unnamed white woman later reinforces as a truth about herself and whiteness in her later interaction with Joanne.

The woman, who eventually identifies herself as Chelsea Peretti, notices Joanne clutching a strand of pearls and asks: "... are those my grandmother's pearls, all entwined in your dirty fingers?"[23] Peretti calls the police and says: "Yes, this is the Peretti residence, there is an intruder in my Caucasian home. Yes, the grand mansion on Caucasian Lane. Please send help, send as many people as you can, our community is in danger."[24] In Peretti identifying herself to the police, her whiteness is constantly adduced, her status as a glamorous Caucasian woman is parallel with her own identification of Joanne as a dangerous "ethnic" woman, as exemplified by her self-referential whiteness and her use of the work "dirty" to describe Joanne-Joanne's racial queerness informs her identity and the way in which she is seen by the outside world. She codes herself as white and attempts to embody white womanhood but is regularly identified by those around her as "ethnic" and not authentically white - a paradigm consistent with Miller's discussion of believing that he was white but being told by outsiders that he was black.

In the closing shot of the video, Joanne flees out of the back door, past the pool, and does a backflip over the security fence. In Caucasian Living with Joanne the Scammer, Miller's performance and Joanne's attempt to embody a glamorous Caucasian woman entails an absurdity. In the world that Miller builds, in his racially queer disidentificatory praxis, to be white is to be a liar, a thief, and ultimately a scammer. His portrayal of delusional 
white womanhood is reflective of the contemporary cultural milieu and the rise of the "Karen" - deceitful white women who weaponize their whiteness to enact racialized violence against black and other people of color through the locus of the police, or extralegal means. Miller not only "cracks open" the code of whiteness associated with being a glamorous Caucasian woman, but he uses the code in a way that deviates from heteropatriarchal norms; he uses blackface reversal, drag, and farce to underline the absurdity of white supremacy.

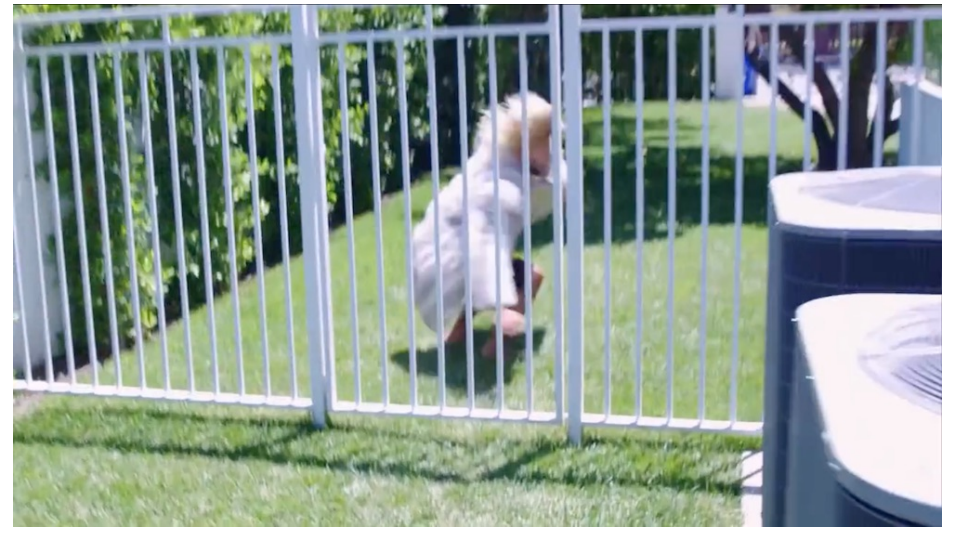

Figure 2. Still taken from Caucasian Living with Joanne the Scammer.
Miller's critique of whiteness and white supremacy is further explored in Untitled (2016), a short advertisement circulated on Twitter and YouTube and produced by Super Deluxe. In the video, which was posted in the wake of the 2016 United States presidential election, a haughty fur-wearing Joanne triumphantly glides through a darkened sweatshop full of brown skinned Latinx workers who glare at her as they sew welcome mats embroidered with the words: "Get Out of My Caucasian House." Joanne picks up one of the rugs and declares it to be "iconic." One of the workers finishes a rug and throws it at Joanne's feet before returning to her

work. A voiceover of Joanne declares: "The Official Get Out of My Caucasian House welcome mat. From Joanne the Scammer, made in the USA, it's glamorous, I promise."[25] The video is both self-aware in its allusions to Joanne's racial politics, and an overtly political critique of the right-wing white nationalistic and anti-immigration rhetoric that was responsible for the "change" in the social and political landscape of the United States in the wake of the 2016 presidential election. ${ }^{[26]}$ the proceeds from the sale of the rugs are to be donated to the American Civil Liberties Union.

Branden Miller's performance modality is a racially queer disidentificatory practice embedded in a performance of identity that critiques class, whiteness, and white supremacy. In "“Quare" Studies, or (almost) Everything I Know about Queer Studies I Learned from My Grandmother," E. Patrick Johnson reminds us that black people have always forged innovative ways of engaging disidentificatory practice to work against "oppressive institutional structures."[27] This tradition of black disidentificatory practice can be traced back to the ways in which enslaved black people used spirituality and other art forms such as folktales and the blues as a "foundation for social and political empowerment." [28] These "discursively mediated" forms of performance became metaphoric "discursive weapons" once expressed through the locus of the enslaved black body so that seemingly unobjectionable spirituals or folktales became literal guides for liberation. ${ }^{[29]}$ Furthermore, Johnson argues that LGBT people of color have always found "vernacular tools" that enabled them to transcend their material conditions, and these "vernacular tools" have consistently transformed as they have fought against oppressive power structures. [30] Miller's cultural production is part of a genealogy that has always found new tools to use disidentificatory practice to critique white supremacist institutions. In Miller's black queer worldview, whiteness and white supremacy are scams, and he constructs it by engaging a racially queer cultural code that reveals whiteness through the use of drag, farce, and blackface reversal. The brilliance of Joanne as a character is that she is unable to be pinned down; she is a racially ambiguous "messy bitch who lives for drama" and completely disorients the ways in which we think race, gender, sexuality, and class. In articulating this argument, I have looked at three objects from 
Miller's cultural archive: The Joanne the Scammer Network with Joanne the Scammer (2016), Caucasian Living with Joanne the Scammer (2016), and Untitled (2016). These videos, while short, are salient depictions of the argument that I make in this article. In building this construction of Branden Miller's performance of Joanne the Scammer as a racially queer disidentificatory practice, I have also explored the intersection between black queer cultural production and Digital Blackness. Theorization about the digital world as a locus from which to understand the black experience and even more specifically, the black queer experience, is significant and may provide a way for us to imagine the place of Digital Blackness within queer of color critique. In the short story "Evidence" Alexis Pauline Gumbs writes that "...technology is the brilliance of making something out of anything." [31] Certainly, the fears and anxieties that Hemphill and Sharpe expressed about cyberspace in the mid to late 90 s have come to fruition as video and images of black suffering and death are often widely circulated on the internet in the wake of legal and extralegal murders of black people by the police and the white actors that state power empowers to police black bodies. Yet, as Gumbs reminds us, the great thing about technology is the ability to take it and form it into something generative that can be a site of possibility and empowerment. Miller brilliantly uses technology, and he uses it blackly and queerly to tell us something about the world in which we live through a praxis located in a messy, sometimes-outlandish, humor that cracks open the code of whiteness and reveals it for what it is-a scam.

\section{Bibliography}

Black Nations/Queer Nations? Lesbian and Gay Sexualities in the African Diaspora. Directed by Shari Frilot. United States: Third World Newsreel, 1995.

Brock, André L.Distributed Blackness: African American Cybercultures. New York: New York University Press, 2020.

Caucasian Living with Joanne the Scammer. Performed by Branden Miller. YouTube. August 17, 2016. Accessed December 2, 2016. https://www.youtube.com/watch?v=IVPAkv0V9Ak.

Chang, Aurora. "Reflections of a Racial Queer." Multicultural Perspectives 12, no. 2 (2010).

Gumbs, Alexis Pauline. "Evidence," inOctavia's Brood: Science Fiction Stories from Social Justice Movements. Oakland: AK Press, 2015.

Hobson, Janell. “Digital Whiteness, Primitive Blackness.” Feminist Media Studies8, no. 2 (2008): 111-26.

Johnson, Patrick E. “"Quare” Studies, or (Almost) Everything I Know about Queer Studies I Learned from My Grandmother." Text and Performance Quarterly 21, no. 1 (2001).

McDermott, Patrick D. "Joanne the Scammer Lives for Drama. Branden Miller Is Just Trying to Live." The Fader. August 12, 2016. https://www.thefader.com/2016/08/09/joanne-the-scammer-branden-miller-messy-bitchinterview. 
Miller, Branden. Instagram. December 2015. Accessed July 05, 2020.

https://www.instagram.com/p/_QWXb5tFoJ/?hl=en.

Muñoz, José Esteban. Disidentifications Queers of Color and the Performance of Politics. Minneapolis: University of Minnesota Press, 2015.

O'Donnell, Carey. "Talking Business with Social Media Prophet Joanne the Scammer." PAPER. March 28, 2016. Accessed December 09, 2016. https://www.papermag.com/joanne-the-scammer-1692717936.html.

Pérez Huber, Lindsay. "Make America Great Again: Donald Trump, Racist Nativism and the Virulent Adherence to White Supremacy amid US Demographic Change." Charleston Law Review 10 (2016).

Scammer, Joanne The. "Not so Caucasian Tonight Betch. On My Way to the Drug Lords House, Little Does He Know under This Is a Blonde Bob. Pic.twitter.com/UirgzoRLof." Twitter. September 11, 2016. Accessed July 05, 2020. https://twitter.com/joanneprada/status/774765683192266753.

Sharpe, Christina Elizabeth. "Racialized Fantasies on the Internet." Signs: Journal of Women in Culture and Society 24, no. 4 (1999): 1089-096. doi:10.1086/495406.

The Joanne Scamming Network with Joanne the Scammer. Produced by Branden Miller, Jason Richards, and Callum Hanlon. Performed by Branden Miller. YouTube. September 2, 2016. Accessed December 2, 2016. https://www.youtube.com/watch?v=8BQwBnxcPiA.

Untitled. Performed by Branden Miller. Twitter. November 14, 2016. Accessed December 2, 2016. https://twitter.com/joanneprada/status/798350980098052096.

\section{Notes}

1. Branden Miller. Instagram Post. December 2015. https://www.instagram.com/p/_QWXb5tFoJ/?hl=en

2. Black Nations/Queer Nations? Lesbian and Gay Sexualities in the African Diaspora, dir. Shari Frilot (United States: Third World Newsreel, 1995).

3. Christina Elizabeth Sharpe, "Racialized Fantasies on the Internet," Signs: Journal of Women in Culture and Society 24, no. 4 (1999): |PAGE|, p.1089).

4. Ibid., 1089.

5. Janell Hobson, "Digital Whiteness, Primitive Blackness," Feminist Media Studies8, no. 2 (2008): |PAGE|, p.112).

6. André L. Brock,Distributed Blackness: African American Cybercultures(New York: New York University Press, 2020), |PAGE|, p.1).

7. Patrick D. McDermott, “Joanne The Scammer Lives For Drama. Branden Miller Is Just Trying To Live." The FADER. August 12, 2016, https://www.thefader.com/2016/08/09/joanne-the-scammer-branden-millermessy-bitch-interview.com.

8. Branden Miller, Twitter Post. September 10, 2016, 5:25 PM. https://twitter.com/joanneprada/status/774765683192266753.

9. The Joanne Scamming Network with Joanne the Scammer. By Branden Miller, Jason Richards, and Callum Hanlon. Performed by Branden Miller. YouTube. September 2, 2016. Accessed December 2, 2016. 
10. Ibid., 0:29-0:37.

11. Ibid., 1:58-2:03.

12. Ibid., 3:28-3:34.

13. José Esteban. Muñoz, Disidentifications Queers of Color and the Performance of Politics (Minneapolis: University of Minnesota Press, 1999), |PAGE|, p.28).

14. Ibid. 31.

15. Caucasian Living with Joanne the Scammer. Performed by Branden Miller. YouTube. August 17, 2016. Accessed December 2, 2016, https://www.youtube.com/watch?v=IVPAkv0V9Ak.

16. Ibid., 1:29-1:42.

17. Aurora Chang, "Reflections of a Racial Queer," Multicultural Perspectives12, no. 2 (2010): |PAGE|, p.111).

18. Ibid.111.

19. Caucasian Living with Joanne the Scammer, 1:50-1:59.

20. Ibid., 2:25-2:34.

21. Joanne's relationship with Kirstie Alley materializes into the real world. In a tweet from August 23rd, 2016, Kirstie Alley herself responds to a video of Joanne planning a scam and says: "hit me up." See Kirstie Alley, Twitter Post. August 23, 2016, 10:40 PM, https://twitter.com/kirstiealley/status/768321979120181248.

22. Caucasian Living, 5:21-5:26.

23. Ibid., 5:43-5:47.

24. Ibid., 5:54-6:07.

25. Untitled. Performed by Branden Miller. Twitter. November 14, 2016. Accessed December 2, 2016. https://twitter.com/joanneprada/status/798350980098052096. (1:14-1:25).

26. Lindsay Pérez Huber, "Make America great again: Donald Trump, racist nativism and the virulent adherence to white supremacy amid US demographic change." Charleston L. Rev.10 (2016): |PAGE|, p. 215.

27. E. Patrick Johnson, “"Quare” Studies, or (almost) Everything I Know about Queer Studies I Learned from My Grandmother." Text and Performance Quarterly 21, no. 1 (2001): |PAGE|, p. 120.

28. Ibid., 12.

29. Ibid., 12.

30. Ibid., 13.

31. Alexis Pauline Gumbs, "Evidence," in Octavia's Brood: Science Fiction Stories from Social Justice Movements (Oakland, California: AK Press, 2015): |PAGE|, pg. 39.

\section{Cite this Essay}

King-Carroll, Kidiocus. "Scams, Heists, and Racial Disidentification: Joanne the Scammer at the Intersection of Queer of Color Critique and Digital Blackness." Rhizomes: Cultural Studies in Emerging Knowledge, no. 37, 2021, doi:10.20415/rhiz/037.e04

RHIZOMES ISSN 1555-9998 ^ 230 East Hall Bowling Green State University Bowling Green, OH 43403

Editors: Ellen Berry and Carol Siegel. Reviews editor: Craig J. Saper. Technical editor: Helen J Burgess 